\title{
Acidophilic algae isolated from mine-impacted environments and their roles in sustaining heterotrophic acidophiles
}

\author{
Ivan Ňancucheo ${ }^{1,2}$ and D. Barrie Johnson ${ }^{1 *}$ \\ 1 School of Biological Sciences, Bangor University, Bangor, UK \\ ${ }^{2}$ Agriculture of Desert and Biotechnology, Universidad Arturo Prat, lquique, Chile
}

Edited by:

Ricardo Amils, Universidad

Autónoma de Madrid, Spain

\section{Reviewed by:}

John Stolz, Duquesne University, USA

Kenneth Stedman, Portland State University, USA

\section{*Correspondence:}

D. Barrie Johnson, School of Biological Sciences, Bangor

University, Bangor LL57 2UW, UK. e-mail:d.b.johnson@bangor.ac.uk
Two acidophilic algae, identified as strains of Chlorella protothecoides var. acidicola and Euglena mutabilis, were isolated in pure culture from abandoned copper mines in Spain and Wales and grown in $\mathrm{pH}$ - and temperature-controlled bioreactors. The Chlorella isolate grew optimally at $\mathrm{pH} 2.5$ and $30^{\circ} \mathrm{C}$, with a corresponding culture doubling time of $9 \mathrm{~h}$. The isolates displayed similar tolerance $(10-50 \mathrm{mM})$ to four transition metals tested. Growth of the algae in liquid media was paralleled with increasing concentrations of dissolved organic carbon (DOC). Glycolic acid was identified as a significant component (12-14\%) of total DOC. Protracted incubation resulted in concentrations of glycolic acid declining in both cases, and glycolic acid added to a culture of Chlorella incubated in the dark was taken up by the alga ( $100 \%$ within 3 days). Two monosaccharides were identified in cell-free liquors of each algal isolate: fructose and glucose (Chlorella), and mannitol and glucose (Euglena). These were rapidly metabolized by acidophilic heterotrophic bacteria (Acidiphilium and Acidobacterium spp.) though only fructose was utilized by the more fastidious heterotroph "Acidocella aromatica." The significance of algae in promoting the growth of iron- (and sulfate-) reducing heterotrophic acidophiles that are important in remediating mine-impacted waters (MIWs) is discussed.

Keywords: acidophilic algae, Chlorella, Euglena, glycolic acid, microbial interactions, mine waters, monosaccharides

\section{INTRODUCTION}

Mining of metals and coal can impair the environment in many ways. One of the most widely documented is the generation of mine-impacted water bodies (MIWs; drainage streams and pit lakes) that are characteristically acidic (sometimes extremely so) and which contain elevated concentrations of iron and other transition metals, aluminium, sulfate, and sometime arsenic. These constitute an "extreme" environment, which is hostile to most life forms (reviewed in Johnson, 2009). In the most severe cases, indigenous organisms are exclusively microbial and predominantly prokaryotic. Eukaryotic microorganisms, including acidophilic and acid-tolerant species of microalgae, fungi and yeasts, protozoa and rotifera, have, however, been reported in MIWs on a number of occasions (e.g., Baker et al., 2004; Aguilera et al., 2007; Das et al., 2009).

Primary production in MIWs is mediated by autotrophic microorganisms that use either solar or chemical energy to fuel carbon dioxide fixation. In subterranean locations, chemolithotrophic acidophilic bacteria and archaea that use ferrous iron, reduced sulfur (and possibly hydrogen) as electron donors are the sole agents of primary production (e.g., Bond et al., 2000; Johnson, 2012). Mechanisms of carbon fixation and other physiological characteristics of bacteria such as Acidithiobacillus spp. and Leptospirillum spp. have been well studied, not only because these mineral-oxidizing acidophiles are generally acknowledged to be the most important microorganisms involved in the genesis of MIWs, but also because the same bacteria are considered to be the most significant agents of metal extraction in commercial "biomining" operations (Rawlings and Johnson, 2007). However, where solar energy is available, net carbon fixation by acidophilic microalgae may exceed that of chemolithotrophic bacteria, since the most abundant chemical energy source in the most acidic mine waters (ferrous iron) is a relatively poor electron donor in terms of free energy ( $\Delta \mathrm{F}_{298}$ of $-73 \mathrm{~kJ}$; Kelly, 1978$)$.

The biodiversity of validated species of acidophilic and acidtolerant algae is relatively limited (reviewed in Novis and Harding, 2007). Micro-algae reported to be metabolically active in metalrich, highly acidic environments include some Chlorophyta, such as Chlamydomonas acidophila and Dunaliella acidophila, Chrysophyta, such as Ochromonas sp., and Euglenophyta, such as Euglena mutabilis. Some diatoms, including several Eunotia spp., have also been found to colonize extremely acidic waters. Filamentous algae, identified as Zygnema circumcarinatum and Klebsormidium acidophilum, have been found in extremely acidic $(\mathrm{pH}<3)$ mine waters in Spain and New Zealand, respectively (Novis and Harding, 2007; Rowe et al., 2007). Moderately thermophilic and acidophilic Rhodophyta (Cyanidium caldarium, 
Galdieria sulfuraria, and Galdieria maxima) are frequently encountered in acidic waters in geothermal areas (Toplin et al., 2008). In contrast to acidophilic autotrophic bacteria, there have been few reports of laboratory studies of axenic cultures of acidophilic microalgae, presumably due to difficulties in obtaining cultures of these eukaryotes that are free of bacteria. Axenic cultures are necessary, for example, to identify and quantify the amounts of organic carbon released by acidophilic algae, a phenomenon that has previously been reported for chemolithotrophic acidophiles (e.g., Nancucheo and Johnson, 2010).

Macroscopic growths of acidophilic algae have been reported in various streams and rivers in the Iberian Pyrite Belt (IBP) in south-western Spain. Aguilera et al. (2007) found that the diversity of indigenous algae in biofilm growths was related to the acidity and metal contents of sites within the Rio Tinto, and that algal populations displayed seasonal trends. Initially, biofilm growths were dominated by flagellated green algae (Dunaliella or Chlamydomonas), and Euglena. Later sessile species of algae such as Chlorella and Cyanidium appeared, followed lastly by filamentous algae (Zygnemopsis and Klebsormidium). Elsewhere in the IBP, Rowe et al. (2007) reported that an open drainage channel at an abandoned copper mine (Cantareras) contained a thick $(\sim 12 \mathrm{~cm})$ microbial mat, the upper layer $(\sim 2.5 \mathrm{~mm})$ of which was green colored and contained both unicellular (Euglena and Chlamydomonas) and filamentous (Zygnema) micro-algae. The mat under the algal layer was bacterial, and dominated by heterotrophic acidophiles (including species of ferric ironand sulfate-reducing bacteria). With increasing distance from the mine adit, algae were rare or absent, and this correlated with a much less thick (or absent) microbial mat within the drain channel. The inference was made that the autotrophic algae were providing the organic materials that sustained the heterotrophic acidophiles in the microbial mat, as the concentration of dissolved organic carbon (DOC) in the mine water at its point of discharge was very low $(\sim 1 \mathrm{mg} / \mathrm{L})$.

Here we describe the isolation, in pure culture, of strains of two acidophilic algae (Chlorella protothecoides var. acidicola and Euglena mutabilis) from MIWs in Spain and Wales, the nature of their organic exudates and lysates, and the significance of the latter in sustaining heterotrophic bacteria in acidic mine waters.

\section{MATERIALS AND METHODS ORIGINS, ISOLATION, AND CULTIVATION OF ACIDOPHILIC ALGAE}

The two acidophilic algae investigated in the present study were isolated from extremely acidic ( $\mathrm{pH}$ 2.5-2.6) MIWs draining abandoned copper mines in Europe. Chlorella protothecoides var. acidicola was isolated from surface growths of a microbial mat at Cantareras, Spain (Rowe et al., 2007; Figure 1A) while Euglena mutabilis was isolated from green streamer-like growths at Mynydd Parys, Wales (Coupland and Johnson, 2004; Figure 1B). In both cases, small algal growths were removed using sterile tweezers, suspended in acidic ( $\mathrm{pH} 2.5)$ basal salts and dispersed by vortexing. Cell suspensions were then streaked onto a solid medium containing acidified ( $\mathrm{pH}$ 2.5) basal salts and trace elements (Wakeman et al., 2008) supplemented with $100 \mu \mathrm{M}$ ferrous sulfate (aBS/TE), and gelled with $0.5 \%(\mathrm{w} / \mathrm{v})$

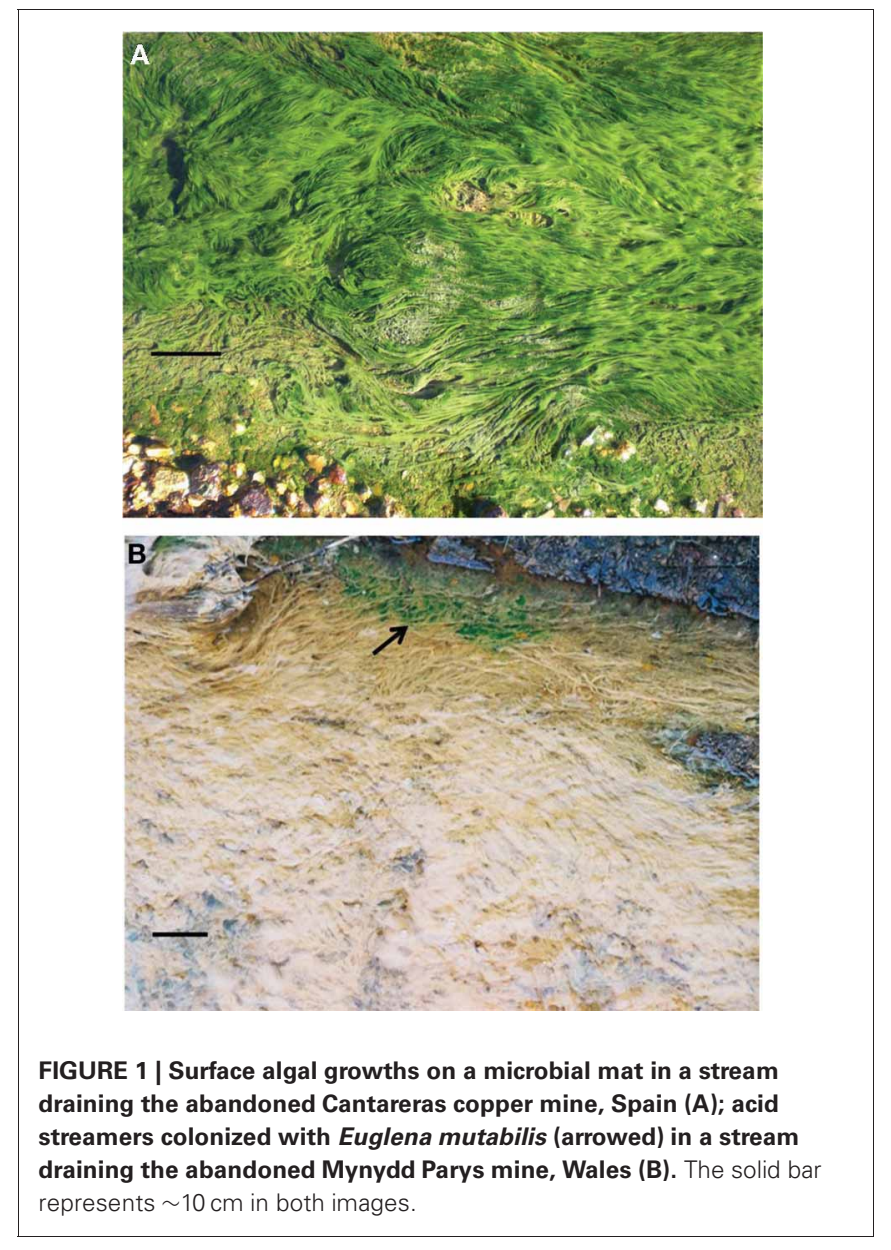

agarose (Sigma type I). The $\mathrm{pH}$ of the gelled medium, measured with a flat bottomed combination $\mathrm{pH}$ electrode (Russell $\mathrm{pH}, \mathrm{UK})$ was $\sim 2.8$. Plates were incubated at $22^{\circ} \mathrm{C}$ under a light bank with constant illumination $\left(70 \mu \mathrm{mol}\right.$ of photons $\left.\mathrm{m}^{-2} \mathrm{~s}^{-1}\right)$. After $\sim 20$ days, small green-colored colonies were apparent. These were re-streaked onto fresh plates, and single colonies from these placed into aBS/TE liquid medium $(25 \mathrm{~mL}$ in $100 \mathrm{~mL}$ conical flasks) and incubated under light. Microscopic examination showed that bacteria, as well as single eukaryotic cell morphologies, were present, in grown cultures. To eliminate the bacteria, the micro-algae were cultivated in aBS/TE medium containing various mixtures of antibiotics [ampicillin (100, 300, and $500 \mu \mathrm{g} / \mathrm{mL}$ ) supplemented (or not) with $100 \mu \mathrm{g} / \mathrm{mL}$ of streptomycin]. This procedure was repeated until no bacteria were observed by phase contrast microscopy and when algal cultures were inoculated into media that support the growth of acidophilic bacteria (Johnson and Hallberg, 2007). Aliquots of purified liquid cultures were streak-inoculated onto solid medium, and single colonies from these placed into liquid aBS/TE medium containing no antibiotics. Cultures were checked routinely for the presence of bacteria throughout the course of the experiments.

The identities of the algal isolates were confirmed by amplification and sequencing of their $18 \mathrm{~S}$ rRNA genes. Genes 
were amplified by PCR (30 cycles; denaturation for $30 \mathrm{~s}$ at $95^{\circ} \mathrm{C}$, annealing for $30 \mathrm{~s}$ at $55^{\circ} \mathrm{C}$, and elongation at $72^{\circ} \mathrm{C}$ for $90 \mathrm{~s}$, followed by $10 \mathrm{~min}$ period at $72^{\circ} \mathrm{C}$ ). The primers used, EukF (ACCTGGTTGATCCTGCAG) and EukR (TGATCCTT CYGCAGGTTCAC), were modified versions of those described by Medlin et al. (1988). Gene sequences were determined using a Beckman Coulter dye terminator cycle sequencing kit and a CEQ8000 Genetic Analysis System (Beckman Coulter, UK) and were compared with those in public databases using BLAST.

\section{BIOREACTOR CULTURES OF ACIDOPHILIC ALGAE}

Purified cultures of the two acidophilic algal isolates were grown in aBS/TE liquid medium in a $2 \mathrm{~L}$ (working volume) FerMac 200 modular bioreactor (Electrolab, UK) under constant illumination. For routine cultivation, the Chlorella isolate was grown at $\mathrm{pH} 2.5$ and at $25^{\circ} \mathrm{C}$, and cultures were aerated at $200 \mathrm{~mL} / \mathrm{min}$ and stirred at $75 \mathrm{rpm}$. The Euglena isolate was grown under the same conditions, but without stirring. To determine the effects of $\mathrm{pH}$ and temperature on the growth of the Chlorella isolate, cultures were grown at: (1) a fixed temperature of $25^{\circ} \mathrm{C}$ and varying (and fixed) $\mathrm{pH}(2.0-3.5)$, and (2) a fixed $\mathrm{pH}$ of 2.5 and temperature ranging from 22 to $35^{\circ} \mathrm{C}$. Samples were removed from the reactor at regular intervals and cell numbers determined initially both by enumerating cells (using a Helber counting chamber marked with Thoma ruling (Hawksley, UK) and viewed with a Leitz Labolux phase contrast microscope, at a magnification of $\times 400$ ) and by measuring the optical densities (OD) of cultures at $600 \mathrm{~nm}$. Since the two measurements were found to be highly correlated (data not shown), only OD measurements were made in later experiments. Culture doubling times were evaluated from semi-logarithmic plots of cell number increase against time. Attempts to carry out parallel growth response experiments with the Euglena isolate were not successful as mechanical agitation (stirring) of the bioreactor was found to impede the growth of this alga (possibly due to physical damage to the cells), and consequently this isolate did not grow as dispersed planktonic phase cells, precluding accurate determination of cell numbers.

\section{EFFECT OF SOME TRANSITION METALS ON THE GROWTH OF ALGAL ISOLATES}

Isolates were grown in aBS/TE liquid medium $(5 \mathrm{~mL}$ aliquots in $25 \mathrm{ml}$ universal bottles) containing different concentrations $(0,10,50,100$, and $200 \mathrm{mM})$ of transition metals $\left(\mathrm{Cu}^{2+}, \mathrm{Fe}^{2+}\right.$, $\mathrm{Fe}^{3+}, \mathrm{Ni}^{2+}$, or $\mathrm{Zn}^{2+}$, all added as sulfates). The cultures were set at $\mathrm{pH} 2.5$ and were incubated at $22^{\circ} \mathrm{C}$, shaken $(100 \mathrm{rpm})$ for 30 days. Growth of the micro-algae was assessed by microscopic examination of the cultures.

\section{DISSOLVED ORGANIC CARBON IN CULTURES OF ALGAL ISOLATES}

Isolates were grown in a bioreactor for 60 days (the Chlorella isolate) or 90 days (the Euglena isolate), the cultures removed and cell-free liquors obtained by centrifugation $(10,000 \times \mathrm{g} ; 15 \mathrm{~min})$ followed by filtration through $0.2 \mu \mathrm{m}$ (pore size) cellulose nitrate membrane filters (Whatman, UK). Concentrations of total DOC in cell-free culture liquors were measured using a LABTOC DOC analyzer (Pollution and Process Monitoring, UK). Glycolic acid and other aliphatic acids were determined using a combination of ion chromatography and colorimetry (Nancucheo and Johnson, 2010). Carbohydrates and amino acids were determined using a Dionex ICS 3000 ion chromatograph fitted with an ED amperometric detector. Separation of sugars was carried out on a Dionex CarboPac MA1 column with a CarboPac MA1 guard column, eluted with $0.25 \mathrm{mM}$ sodium hydroxide $(0.4 \mathrm{~mL} / \mathrm{min})$, and amino acids were separated on a Dionex AminoPAC PA10 column.

\section{METABOLISM OF GLYCOLIC ACID BY THE CHLORELLA AND EUGLENA ISOLATES}

The Chlorella isolate was grown in a bioreactor, as described above, for 20 days. On day 20, the light source was removed, and on day 22 glycolic acid was added to give a concentration of $0.5 \mathrm{mM}$ in the reactor vessel. The light source was reinstated on day 25. Samples were withdrawn at regular intervals to measure the concentrations of total DOC and glycolic acid, and to determine OD.

\section{METABOLISM OF ALGAL DOC BY ACIDOPHILIC HETEROTROPHIC BACTERIA}

The acidophilic, iron-reducing heterotrophic bacteria Acidiphilium SJH (Bridge and Johnson, 2000), "Acidocella (Ac.) aromatica" strain PFBC (Coupland and Johnson, 2008) and the type strain of Acidobacterium (Ab.) capsulatum (Kishimoto et al., 1991) were sourced from the Acidophile Culture Collection maintained at Bangor University, and assessed for their abilities to metabolize DOC present in the algal cultures. Cell-free culture liquors were prepared as above, adjusted to $\mathrm{pH} 3.0$ with $1 \mathrm{M}$ $\mathrm{NaOH}$, and $20 \mathrm{~mL}$ aliquots dispensed into $100 \mathrm{~mL}$ conical flasks. These were inoculated (duplicate cultures) with each of the three heterotrophic bacteria, and a fourth set used as sterile controls. Cultures were incubated with shaking $(150 \mathrm{rpm})$ at $30^{\circ} \mathrm{C}$ for up 6 days and samples were withdrawn at days 0,3 , and 6 to enumerate bacterial cells (total counts, as above) and concentrations of total DOC and monosaccharides.

\section{RESULTS}

\section{IDENTIFICATION OF ACIDOPHILIC ALGAL ISOLATES}

Green-pigmented colonies were observed after 10-14 days on gelled "inorganic" solid media inoculated with surface streamer growths from both Cantareras and Mynydd Parys, and incubated in the light. After a single transfer on solid medium and inoculation into liquid media, cultures of the micro-algae were found to be contaminated with bacteria. These were eliminated by subculturing in the presence of both ampicillin $(500 \mu \mathrm{g} / \mathrm{mL})$ and streptomycin $(100 \mu \mathrm{g} / \mathrm{mL})$. Subsequently, axenic cultures of two algal isolates were maintained in liquid medium. One of these grew as single or small groups of round to oval-shaped cells, $\sim 3-5 \mu \mathrm{m}$ diameter, while the other occurred as aggregating worm-like cells, $\sim 30-50 \mu \mathrm{m}$ long, that displayed gliding motility. The identities of these isolates were confirmed by analysis of their $18 \mathrm{~S}$ rRNA genes (1678 nt and $1778 \mathrm{nt}$ gene length products for the Chlorella- and Euglena-like isolates, respectively). The smaller algae shared $99 \%$ gene similarity with Chlorella protothecoides var. acidicola (strain 124, the closest related strain in GenBank) 
which was isolated from acidic ( $\mathrm{pH} 2)$ water at Pisciarelli, Italy (AJ439399; Huss et al., 2002), while the other shared 99\% gene similarity with a strain of Euglena mutabilis (ELC 1) isolated from Lake Caviahue, an acidic water body in Argentina (EU090196; Brankatschk et al., unpublished). The $18 \mathrm{~S}$ rRNA gene sequences of the current isolates have been deposited in GenBank, and have the accession numbers JF694006 (the Chlorella isolate) and JF694007 (the Euglena isolate).

\section{EFFECT OF PH AND TEMPERATURE ON THE GROWTH OF CHLORELLA ISOLATE}

The Chlorella isolate grew between pH 2 and 3.5, and optimally at $\sim \mathrm{pH} 2.5$ (Figure 2A, showing single data points for each $\mathrm{pH}$

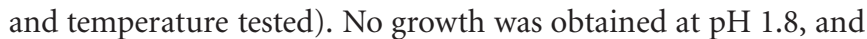
growth above $\mathrm{pH} 3.5$ was not tested. The optimum temperature for growth of this alga was $\sim 30^{\circ} \mathrm{C}$ (Figure $2 \mathbf{B}$ ), and growth was strongly inhibited at $40^{\circ} \mathrm{C}$. Under optimum conditions of $\mathrm{pH}$ and temperature, the Chlorella isolate had a culture doubling time of $9 \mathrm{~h}$. The temperature and $\mathrm{pH}$ characteristics of the Euglena isolate was not determined due to extensive biofilm formation in the growth vessel, though von Dach (1943) had earlier reported

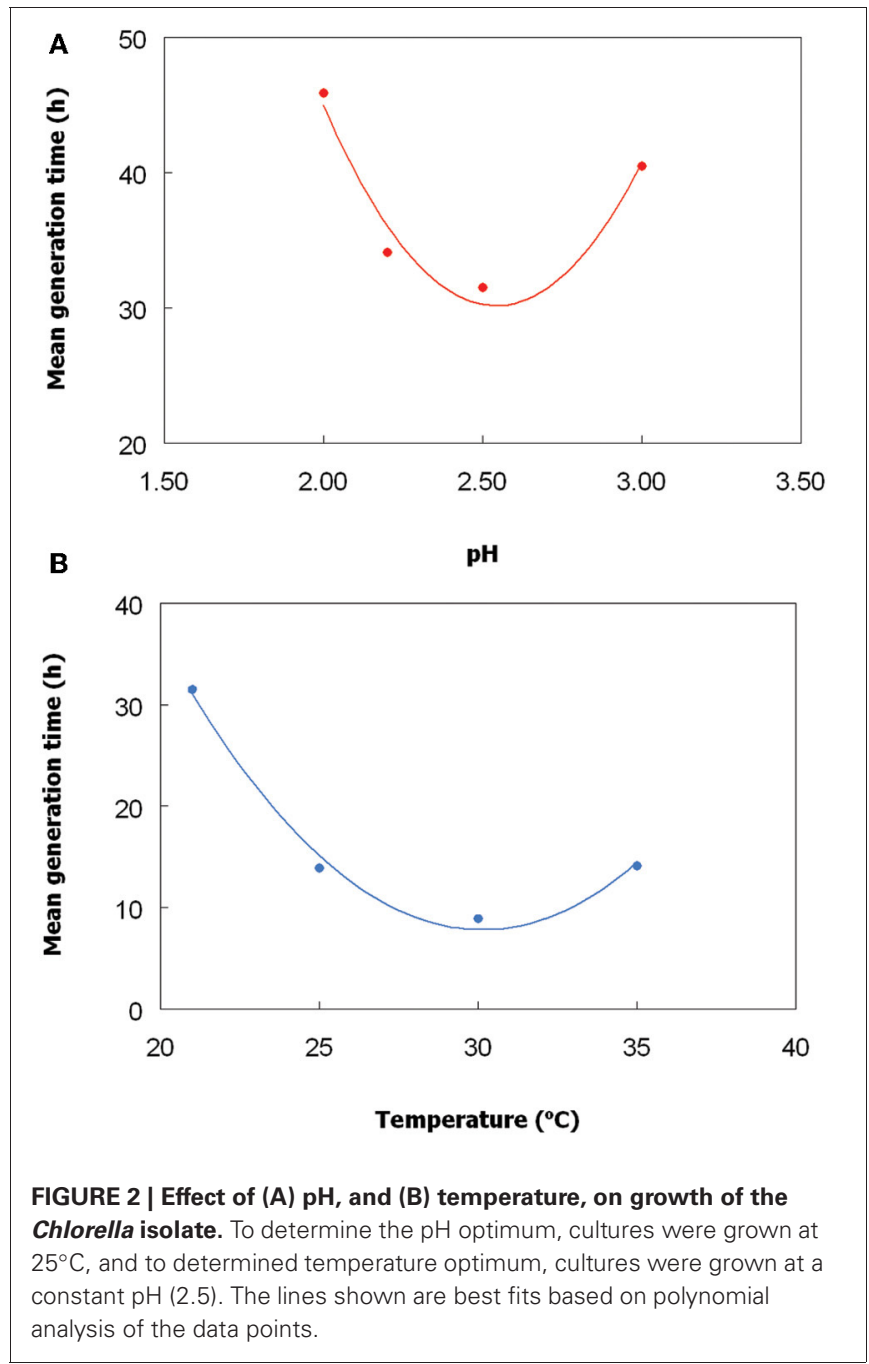

growth of a strain of E. mutabilis between $\mathrm{pH} 2.1$ and 7.7, and optimum growth between $\mathrm{pH} 3.4$ and 5.4.

\section{EFFECTS OF TRANSITION METALS ON GROWTH}

The Chlorella and Euglena isolates showed similar tolerances to the transition metals tested. Both isolates grew in the presence of 10 and $50 \mathrm{mM}$, but not $100 \mathrm{mM}$, of ferrous or ferric iron. Both isolates were more sensitive to copper, zinc, and nickel, with growth being observed in media containing $10 \mathrm{mM}$ but not in $50 \mathrm{mM}$ (or higher concentrations) of these transition metals.

\section{ORGANIC CARBON IN BATCH CULTURES OF CHLORELLA}

Growth of the Chlorella isolate at $\mathrm{pH} 2.5$ and $30^{\circ} \mathrm{C}$ was paralleled by increasing concentrations of DOC, from $4 \mathrm{mg} / \mathrm{L}$ at day 0-30 mg/L at day 19 (Figure 3A). During the first 13 days of culture growth, concentrations of glycolic acid also increased, reaching a maximum value of $120 \mu \mathrm{M}$ (corresponding to $\sim 12 \%$ of total DOC in the cell-free culture liquor). From day 13-15, glycolic acid concentrations fell by $\sim 60 \%$, though this was not

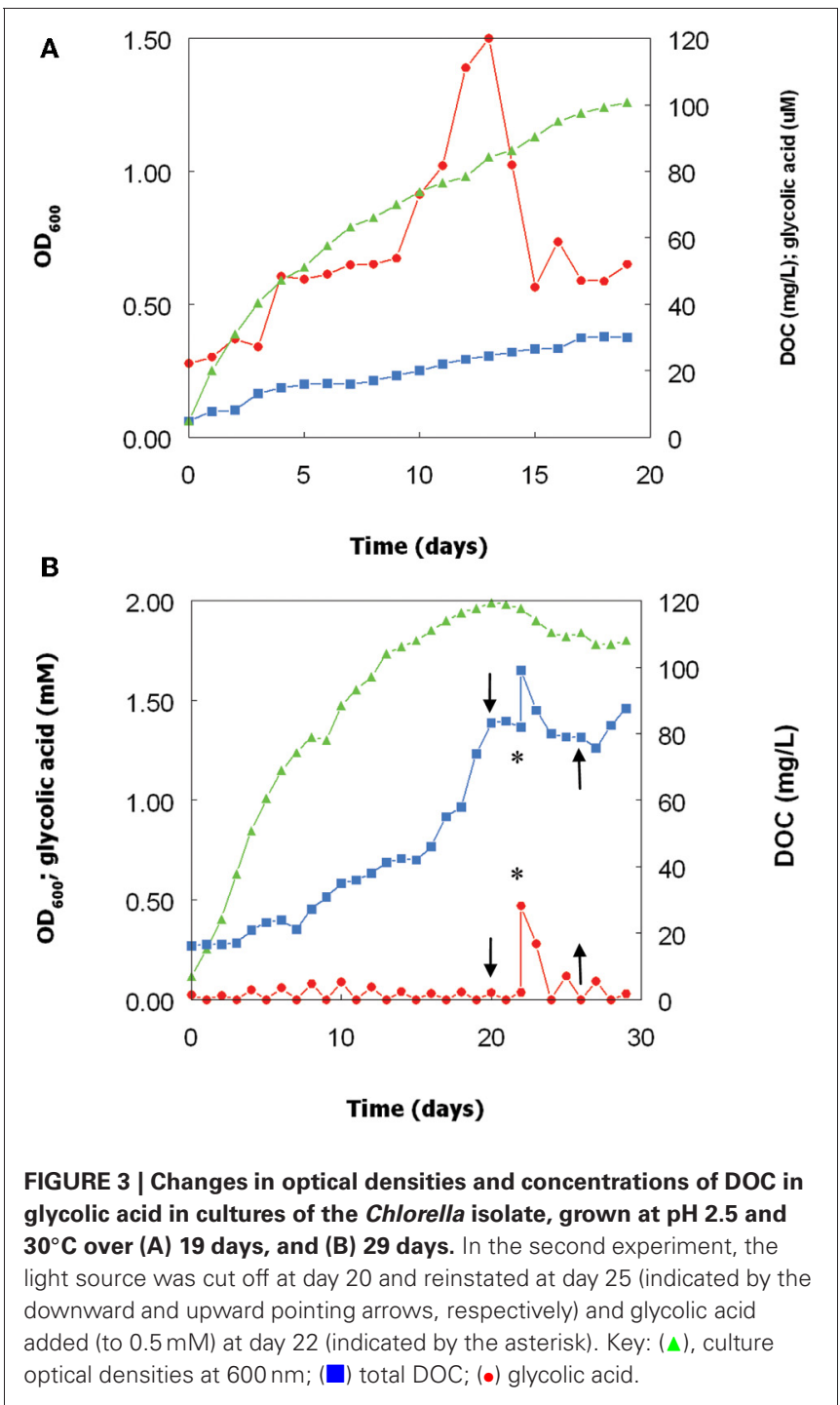


reflected by a lower DOC values. From day 15, the glycolic acid concentrations remained fairly stable, at a level corresponding to about $4 \%$ of total DOC.

A repeat bioreactor experiment was carried out for a more protracted (29 day) period (Figure 3B). Chlorella increased more rapidly than over the first 15 days than in the first experiment, and the DOC concentration was $\sim 60 \%$ greater at day 15 than in the previous experiment. After day 15, growth of the alga slowed down, but the rate of increase of DOC during this period was greater than previously observed. Removing the light source at day 20 resulted in the immediate cessation of both algal growth (followed by a decline in culture optical density) and accumulation of DOC. Glycolic acid, added to the bioreactor culture at day 22 , was found to be quickly removed from solution, with concentrations of both glycolic acid and DOC returning to levels similar to those immediately prior to addition of extraneous glycolic acid by day 25 (Figure 3B). At day 25, the light source was reinstated, which resulted in DOC concentrations again increasing and also, to more limited extent, Chlorella biomass (culture OD).

\section{ORGANIC CARBON IN BATCH CULTURES OF THE EUGLENA ISOLATE}

As with the Chlorella isolate, concentrations of DOC and glycolic acid also increased in bioreactor cultures of the Euglena isolate (Figure 4) though, due to extensive biofilm formation in the growth vessel, these changes could not be directly correlated with growth of this acidophilic alga. As with Chlorella, glycolic acid concentrations increased initially and then stabilized before declining a little, though not to the same extent as in the Chlorella cultures. At day 27, the concentration of glycolic acid in the cellfree culture liquor was equivalent to $14 \%$ of the DOC, but this figure fell to $\sim 7 \%$ by day 45 .

\section{IDENTIFICATION OF OTHER ORGANIC COMPOUNDS IN DOC OF ACIDOPHILIC ALGAL CULTURES}

Besides glycolic acid, the only organic compounds identified in cultures of both the Chlorella and Euglena isolates were monosaccharides. Extensive analysis failed to detect amino acids and other aliphatic acids. Two monosaccharides were detected in each of the

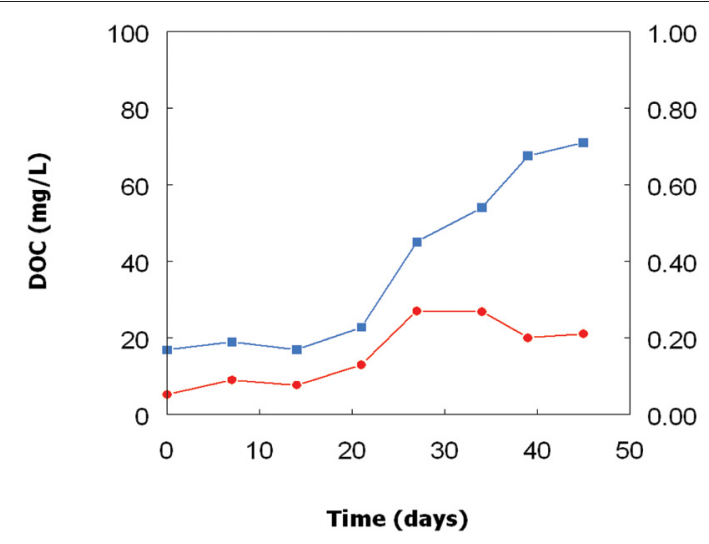

FIGURE 4 | Changes in concentrations of DOC ( $\square$ ) and glycolic acid (•) in a culture of the Euglena mutabilis isolate grown in a bioreactor at $\mathrm{pH} 2.5$ and $30^{\circ} \mathrm{C}$. two algal cultures-fructose and smaller concentrations of glucose in cultures of Chlorella, and mannitol and glucose in cultures of Euglena. In both cases, these accounted for smaller amounts of total DOC than the glycolic acid component (Table 1).

\section{GROWTH OF ACIDOPHILIC HETEROTROPHIC BACTERIA IN CELL-FREE CULTURE LIQUORS OF CHLORELLA AND EUGLENA}

Dissolved organic materials originating from both the Chlorella and Euglena isolates were able to support the growth of representative species of two genera of acidophilic heterotrophic bacteria frequently found in MIWs, Acidiphilium and Acidobacterium, though the species of Acidocella used ("Ac. aromatica" strain PFBC) was only found to grow in cell-free culture liquor of Chlorella (Figure 5). Growth of heterotrophic acidophiles was accompanied by corresponding decreases in concentrations of DOC and monosaccharides (Table 2). In the case of "Ac. aromatica" PFBC, fructose declined to less than detectable concentrations, though those of other sugars were similar after 6 days incubation to initial values. Growth of the different species of heterotrophic acidophiles appeared to correlate with net changes in DOC, with Acidiphilium SJH showing the largest increase in cell numbers and greatest change in DOC concentrations during incubation, and "Ac. aromatica" PFBC the opposite trend. DOC concentrations in cell-free culture liquors of Chlorella declined by between $5 \mathrm{mg} / \mathrm{L}$ (for “Ac. aromatica” PFBC) and $12 \mathrm{mg} / \mathrm{L}$ (for Acidiphilium $\mathrm{SJH}$ ), which was greater than the combined carbon equivalents $(3.2 \mathrm{mg} / \mathrm{L})$ of the two monosaccarides (glucose and fructose) that were analysed. Corresponding data for the Euglena cell-free culture liquors were $17 \mathrm{mg} / \mathrm{L}$ for $A b$. capsulatum and $22 \mathrm{mg} / \mathrm{L}$ for Acidiphilium SJH, compared with a combined carbon equivalent of $7.8 \mathrm{mg} / \mathrm{L}$ for glucose and mannitol (both of which were $>95 \%$ metabolized). These data indicate that other components of the DOC were also utilized by the heterotrophic acidophiles, though this was not the case with "Ac. aromatica" PFBC cultivated in cell-free culture liquor of the Euglena isolate.

\section{DISCUSSION}

Acidophilic micro- algae have widespread distribution in MIWs (Novis and Harding, 2007; Das et al., 2009), though they have been the focus of far less research than prokaryotic acidophiles. One reason for this is that eukaryotes are not directly involved

Table 1 | Monosaccharides identified in cell-free culture liquors of the acidophilic Chlorella and Euglena isolates, determined after 60 and 90 days of culture incubation, respectively.

\begin{tabular}{|c|c|c|c|c|}
\hline & $\begin{array}{l}\text { Concentration } \\
(\mu \mathrm{M})\end{array}$ & $\begin{array}{l}\text { Concentration } \\
\text { (C equivalent; } \\
\mu \mathrm{M} \text { ) }\end{array}$ & $\begin{array}{l}\text { Total DOC } \\
\text { (mg/L) }\end{array}$ & $\begin{array}{l}\text { Contribution } \\
\text { to DOC (\%) }\end{array}$ \\
\hline \multicolumn{5}{|c|}{ CHLORELLA ISOLATE } \\
\hline Glucose & 5 & 0.36 & 167 & 0.22 \\
\hline Fructose & 38.5 & 2.8 & 167 & 1.7 \\
\hline \multicolumn{5}{|c|}{ EUGLENA ISOLATE } \\
\hline Glucose & 65 & 4.7 & 192 & 2.5 \\
\hline Mannitol & 43 & 3.1 & 192 & 1.6 \\
\hline
\end{tabular}




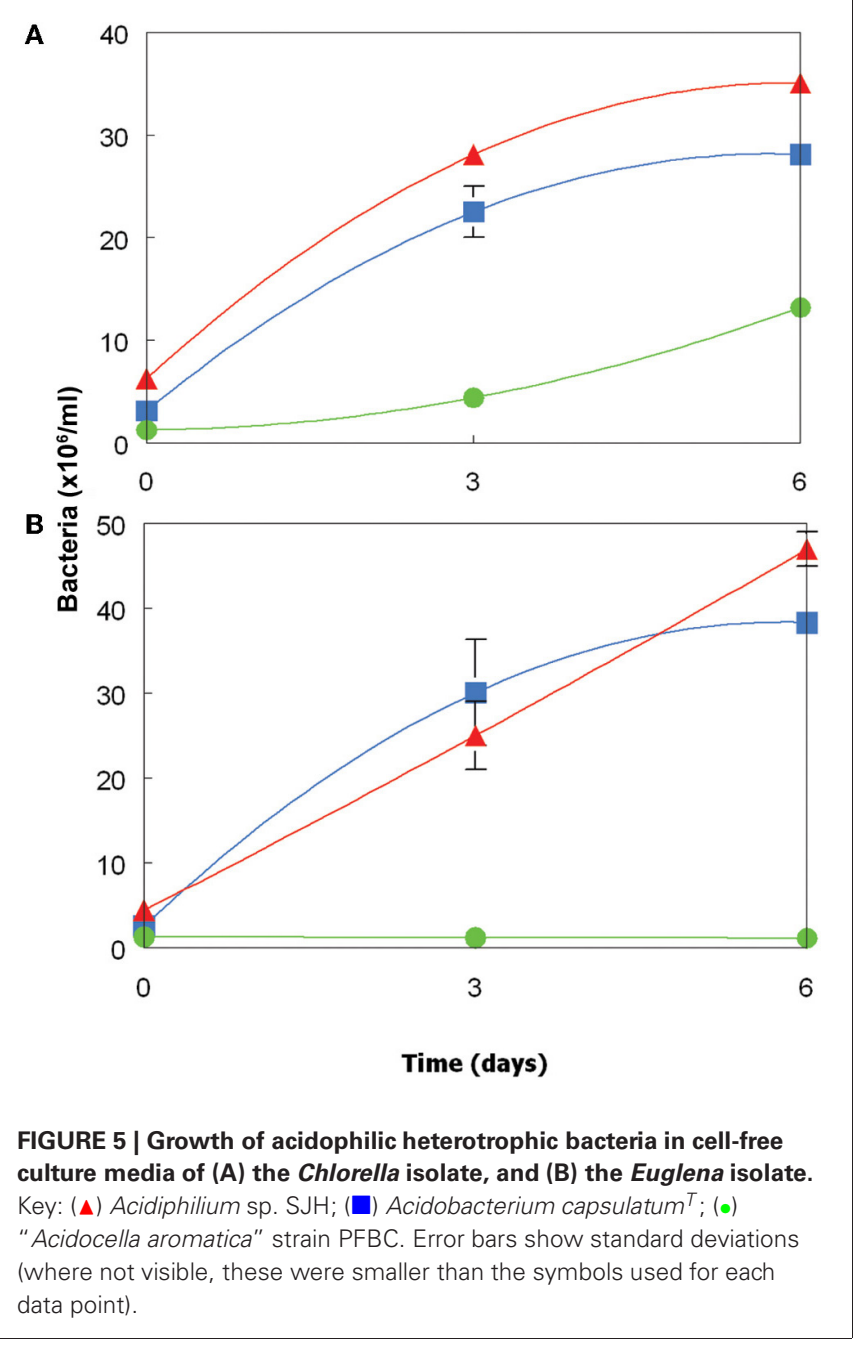

in the geochemical transformations of iron and sulfur that result in the dissolution of sulfide minerals and which give rise to the formation of acid mine drainage waters, as is the case with chemolitho-autotrophic and chemolitho-heterotrophic acidophiles (Johnson and Hallberg, 2009). However, their indirect impact on these transformations can be considerable. Brake et al. (2001) reported that prolific growth of E. mutabilis can lead to MIWs being over-saturated (by up to 200\%) with dissolved oxygen. Waters draining underground mines and adits are frequently devoid of dissolved oxygen, and soluble iron tends to be present predominantly as reduced ferrous iron (Johnson, 2003; Johnson et al., 2012). Oxygenation of MIWs by acidophilic algae facilitates the oxidation of ferrous iron and reduced sulfur compounds present in MIWs by bacteria such as Acidithiobacilllus and Leptospirillum spp., in reactions that are net proton-generating and which can result in further acidification of MIWs downstream of the point of discharge, as described for the Cantareras mine in Spain (Rowe et al., 2007). A second way in which algae can impact geochemical transformations in MIWs is by stimulating the growth of iron- and sulfur-reducing heterotrophic acidophiles via their organic exudates and lysates, as mine waters generally contain very small concentrations of DOC (Johnson, 2003; Das et al., 2009).

There have been many reports describing the global occurrence of E. mutabilis in MIWs, and this organism has frequently been considered as an "indicator species" of acid mine drainage (e.g., Valente and Gomez, 2007). This member of the Protista is a unicellular protozoan, and commonly referred to as an alga (Brake et al., 2001). In addition to being able to grow over a wide pH range (2.1-7.7; von Dach, 1943), E. mutabilis is also tolerant of elevated concentrations of total dissolved solids, including some transition metals and aluminium e.g., Novis and Harding, 2007; Valente and Gomez, 2007). The site from which the current isolate was obtained contains about $500 \mathrm{mg}$ iron (ferrous plus fer$\mathrm{ric}) / \mathrm{L}$ and $50 \mathrm{mg}$ copper/L $(\sim 0.8 \mathrm{mM})$, which are concentrations well below those which inhibited its growth in vitro. In contrast, there are few reports of Chlorella spp. in MIWs, and this alga has been reported to be more prevalent in acidic soils (Huss et al., 2002). Relatively little is known about the physiology of $C$. protothecoides var. acidicola, though Huss et al. (2002) reported that its lower $\mathrm{pH}$ and upper temperature limits for growth are 2.0 and $34^{\circ} \mathrm{C}$, respectively, which are similar to those found in the present study.

Concentrations of DOC increased to similar extents during growth in vitro of both the Euglena and Chlorella isolates. Values obtained were similar to those found in sulfur-grown

Table 2 | Changes in concentrations of DOC and monosaccharides in cell-free culture liquors from the Chlorella and Euglena isolates, inoculated with acidophilic heterotrophic bacteria.

\begin{tabular}{|c|c|c|c|c|}
\hline & Acidiphilium SJH & "Ac. aromatica" PFBC & Ab. capsulatum ${ }^{T}$ & Sterile control \\
\hline \multicolumn{5}{|c|}{ CHLORELLA CELL-FREE CULTURE LIQUOR } \\
\hline DOC (mg/L) Day 0 Day 6 & $167155 \pm 4$ & $167162 \pm 2$ & $167158 \pm 3$ & $167168 \pm 1$ \\
\hline Fructose ( $\mu \mathrm{M})$ Day 0 Day 6 & $38.5<1$ & $38.5<1$ & $38.5<1$ & $38.538 .7 \pm 0.3$ \\
\hline \multicolumn{5}{|c|}{ EUGLENA CELL-FREE CULTURE LIQUOR } \\
\hline Mannitol $(\mu \mathrm{M})$ Day 0 Day 6 & $43<1$ & $4342.4 \pm 0.3$ & $431.9 \pm 0.2$ & $4343.7 \pm 0.5$ \\
\hline
\end{tabular}

" \pm " represent range values of duplicate cultures. 
cultures of the chemolitho-autotrophic bacteria Acidithiobacillus ferrooxidans and Acidithiobacillus caldus (Ňancucheo and Johnson, 2010), though glycolic acid represented a greater proportion of DOC in Chlorella and Euglena cultures (12-14\%) than in cultures of these two bacteria (both $\sim 5 \%$ ). The presumed origin of the glycolic acid in all these acidophiles is due to the activity of RuBisCO which, besides combining carbon dioxide and ribulose bisphosphate (RUBP) also oxidises RUBP to phosphoglyceric acid and phosphoglycolate. Enzymatic hydrolysis of the latter compound produces glycolate, which is exported out of actively growing cells (Fogg and Watt, 1965). In low pH liquors, glycolate is present as undissociated glycolic acid which, in common with acetic and many other small molecular weight aliphatic acids, is highly toxic to most acidophiles (Johnson and Hallberg, 2009). Production and excretion of glycolic acid has previously been reported for neutrophilic micro-algae (Miller et al., 1963; Fogg and Watt, 1965). Among acidophilic prokaryotes, the ability to metabolize glycolic acid appears to be restricted to Firmicutes (e.g., Sulfobacillus spp). None of the three species of heterotrophic acidophiles used in the present study were previously found to grow on this organic acid (Ňancucheo and Johnson, 2010).

Other organic compounds (monosaccharides) identified in cell-free culture liquors of the two algae have more widespread use by heterotrophic acidophiles (Johnson and Hallberg, 2009). Acidiphilium SJH and Ab. capsulatum metabolized fructose and glucose originating from Chlorella, and mannitol and glucose present in the Euglena culture, within 6 days. Mass balance calculations of DOC and sugar concentrations confirmed that other (unidentified) materials were also catabolized by the bacteria during this period. The situation with "Ac. aromatica" PFBC was very different. In contrast to other Acidocella spp, this candidate species grows on a restricted range of substrates, including fructose and some aliphatic acids, but not on glucose or mannitol (Gemmell and Knowles, 2000; Johnson and Hallberg, 2009). While it grew in cell-free culture liquors of Chlorella, only fructose (of the compounds analysed) was metabolized, and its failure to grow in cell-free liquor from Euglena was apparently due to neither mannitol nor glucose being suitable substrates for this acidophile.

\section{REFERENCES}

Aguilera, A., Souza-Egipsy, V., Gomez, F., and Amils, R. (2007). Development and structure of eukaryotic biofilms in an extreme acidic environment, Rio Tinto (SW, Spain). Microb. Ecol. 53, 294-305.

Baker, B. J., Lutz, M. A., Dawson, S. C., Bond, P. L., and Banfield, J. F. (2004). Metabolically active eukaryotic communities on extremely acidic mine drainage. Appl. Environ. Microbiol. 70, 6264-6271.

Bond, P. L., Druschel, G. K., and Banfield, J. F. (2000). Comparison of acid mine drainage communities in physically and geochemically distinct ecosystems. Appl. Environ. Microbiol. 66, 4962-4971.
Brake, S. S., Donnelly, H. K., and Connors, K. A. (2001). Controls on the nature and distribution of an alga in coal mine-waste environments and its potential impact on water quality. Environ. Geol. 40, 458-469.

Bridge, T. A. M., and Johnson, D. B. (2000). Reductive dissolution of ferric iron minerals by Acidiphilium, SJH. Geomicrobiol. J. 17, 193-206.

Coupland, K., and Johnson, D. B. (2004). Geochemistry and microbiology of an impounded subterranean acidic water body at Mynydd Parys, Anglesey, Wales. Geobiology 2, 77-86.

Coupland, K., and Johnson, D. B. (2008). Evidence that the

One of the characteristics of the acidophilic algae studied was their abilities to take up (and presumably to metabolize) glycolic acid that they had previously excreted. This was more closely studied with the Chlorella isolate, where it was shown that extraneous glycolic acid added to a non-photosynthesizing culture was quantitatively removed within 3 days. The ability of some micro-algae to grow as heterotrophs has been widely documented, e.g., Miller et al. (1963) reported that a neutrophilic Chlorella (C. pyrenoidosa) also excreted glycolic acid into its growth medium when cultures were illuminated and that this was taken up rapidly by the algal cells in the absence of light.

The significance of acidophilic micro-algae in sustaining populations of acidophilic heterotrophic bacteria has been illustrated in studies that have compared macroscopic streamer/mat growth in acidic subterranean metal mines and those in sunlight-receiving acid drainage streams (Johnson, 2012). In subterranean sites, where primary production is mediated exclusively by chemolithotrophic acidophiles, streamer growths are often dominated by autotrophic prokaryotes (such as "Ferrovum myxofaciens") whereas micro-algae growing on the surfaces of streamer/mat growths in sunlight-receiving promote the development of underlying microbial communities that are more dominated by heterotrophic acidophiles, including many (Acidiphilium, Acidocella, and Acidobacterium spp.) that catalyze the dissimilatory reduction of ferric iron. Elsewhere, Nancucheo and Johnson (2011) found that sulfidogenesis was far more pronounced in mineral tailings mesocosms that were inoculated with acidophilic algae and acidophilic SRB (aSRB) than with aSRB alone. This provides further support for the hypothesis presented in the present study that acidophilic micro-algae stimulate the growth of acidophilic heterotrophic bacteria by providing them with organic substrates, and suggests that such interactions can be the basis of ecological engineering strategies for prevention and remediation of mine-related metal pollution.

\section{ACKNOWLEDGMENTS}

Ivan Ňancucheo acknowledges the support of the Mecesup Programme of the Chilean Government, and D. Barrie Johnson is grateful to the Royal Society (UK) for the provision of an Industrial Fellowship.

potential for dissimilatory ferric iron reduction is widespread among acidophilic heterotrophic bacteria. FEMS Microbiol. Lett. 279, 30-35.

Das, B. K., Roy, A., Koschorreck, M., Mandal, S. M., Wendt-Potthoff, K., and Bhattacharya, J. (2009). Occurrence and role of algae and fungi in acid mine drainage environment with special reference to metals and sulfate immobilization. Water Res. 43, 883-894.

Fogg, G. E., and Watt, W. D. (1965). Extracellular products of phytoplankton photosynthesis. Proc. $R$. Soc. Lond. B Biol. Sci. 162, 517-534.

Gemmell, R. T., and Knowles, C. J. (2000). Utilisation of aliphatic compounds by acidophilic heterotrophic bacteria. The potential for bioremediation of acidic wastewaters contaminated with toxic organic compounds and heavy metals. FEMS Microbiol. Lett. 192, 185-190.

Huss, V. A. R., Ciniglia, C., Cennamo, P., Cozzolino, S., Pinto, G., and Pollio, A. (2002). Phylogenetic relationships and taxonomic position of Chlorella-like isolates from low $\mathrm{pH}$ environments $(\mathrm{pH}<3.0)$. BMC Evol. Biol. 2, 13.

Johnson, D. B. (2003). Chemical and microbiological characteristics of mineral spoils and drainage waters at abandoned coal and metal mines. Water Air Soil Pollut. Focus 3, 47-66. 
Johnson, D. B. (2009). "Extremophiles: acid environments," in Encyclopaedia of Microbiology, ed M. Schaechter (Oxford, UK: Elsevier), 107-126.

Johnson, D. B. (2012) Geomicrobiology of extremely acidic subsurface environments. FEMS Microbiol. Ecol. 8, 2-12.

Johnson, D. B., and Hallberg, K. B. (2007). "Techniques for detecting and identifying acidophilic mineraloxidising microorganisms," in Biomining, eds D. E. Rawlings and D. B. Johnson (Heidelberg, Germany: Springer-Verlag), 237-262.

Johnson, D. B., and Hallberg, K. B. (2009). Carbon, iron and sulfur metabolism in acidophilic microorganisms. Adv. Microb. Physiol. 54, 202-256.

Johnson, D. B., Kanao, T., and Hedrich, S. (2012). Redox transformations of iron at extremely low $\mathrm{pH}$ : fundamental and applied aspects. Front. Microbiol. 3:96. doi: 10.3389/fmicb.2012.00096

Kelly, D. P. (1978). "Bioenergetics of chemolithotrophic bacteria," in Companion to Microbiology; Selected Topics for Further Discussion, eds A. T. Bull and P. M. Meadow (London: Longman), 363-386.
Kishimoto, N., Kosako, Y., and Tano, T. (1991). Acidobacterium capsulatum gen. nov., sp. nov.: an acidophilic chemoorganotrophic bacterium containing menaquinone from acidic mineral environment. Curr. Microbiol. 22, 1-7.

Medlin, L., Elwood, H. J., Stickel, S., and Sogin, M. L. (1988). The characterization of enzymatically amplified eukaryotic 16S-like rRNA-coding regions. Gene 71, 491-499.

Miller, R. M., Meyer, C. M., and Tanner, H. A. (1963). Glycolate excretion and uptake by Chlorella. Plant Physiol. 38, 337-367.

Nancucheo, I., and Johnson, D. B. (2010). Production of glycolic acid by chemolithotrophic iron- and sulfur-oxidizing bacteria and its role in delineating and sustaining acidophilic sulfide mineral-oxidizing consortia. Appl. Environ. Microbiol. 76, 461-467.

Nancucheo, I., and Johnson, D. B (2011). Safeguarding reactive mine tailings by ecological engineering: the significance of microbial communities and interactions. App. Environ. Microbiol. 77, 8201-8208.

Novis, P., and Harding, J. S. (2007) "Extreme acidophiles: freshwater algae associated with acid mine drainage," in Algae and Cyanobacteria in Extreme Environments, ed J. Seckbach (Heidelberg, Germany: Springer), 443-463.

Rawlings, D. E., and Johnson, D. B. (2007). Biomining. Heidelberg, Germany: Springer-Verlag.

Rowe, O. F., Sánchez-España, J. Hallberg, K. B., and Johnson, D. B. (2007). Microbial communities and geochemical dynamics in an extremely acidic, metal-rich stream at an abandoned sulfide mine (Huelva, Spain) underpinned by two functional primary production systems. Environ. Microbiol. 9, 1761-1771.

Toplin, J. A., Norris, T. B., Lehr, C. R., McDermott, T. R., and Castenholz, R. W. (2008). Biogeographic and phylogenetic diversity of thermoacidophilic Cyanidiales in Yellowstone National Park, Japan, and New Zealand. Appl. Environ. Microbiol. 74, 2822-2833.

Valente, T. M., and Gomez, C. L. (2007). The role of two acidophilic algae as ecological indicators of acid mine drainage sites. J. Iberian Geol. 33, 283-294.

von Dach, H. (1943). The effect of $\mathrm{pH}$ on pure cultures of Euglena mutabilis. Ohio J. Sci. 43, 46-48.

Wakeman, K., Auvinen, H., and Johnson, D. B. (2008).
Microbiological and geochemical dynamics in simulated heap leaching of a polymetallic sulfide ore. Biotechnol. Bioeng. 101, 739-750.

Conflict of Interest Statement: The authors declare that the research was conducted in the absence of any commercial or financial relationships that could be construed as a potential conflict of interest.

Received: 21 June 2012; accepted: 20 August 2012; published online: 11 September 2012.

Citation: Nancucheo I and Johnson DB (2012) Acidophilic algae isolated from mine-impacted environments and their roles in sustaining heterotrophic acidophiles. Front. Microbio. 3:325. doi: 10.3389/fmicb.2012.00325

This article was submitted to Frontiers in Extreme Microbiology, a specialty of Frontiers in Microbiology.

Copyright (c) 2012 Nancucheo and Johnson. This is an open-access article distributed under the terms of the Creative Commons Attribution License, which permits use, distribution and reproduction in other forums, provided the original authors and source are credited and subject to any copyright notices concerning any third-party graphics etc. 